\title{
Using Simulation for Development of Process Control Systems in Mining
}

\author{
Victor Okolnishnikov*, Sergey Rudometov, Stanislav Shakirov and Sergey Zhuravlev \\ Institute of Computational Technologies SB RAS, 6, Ac. Lavrentieva ave., Novosibirsk, Russia, 630090 \\ ${ }^{*}$ Corresponding author
}

\begin{abstract}
This paper describes our own visual interactive simulation system specialized in simulation of technological processes in mining. A new model of the crushing-grading mill was developed with the help of this simulation system. The model was integrated with a process control system of the crushing-grading mill. The model was used for debugging and testing of the process control system of the crushing-grading mill with the help of different "in-the-loop" ways.
\end{abstract}

Keywords-visual interactive simulation; process control system; mining

\section{INTRODUCTION}

Institute of Computational Technologies of Siberian Branch of the Russian Academy of Sciences in Novosibirsk (ICT) develops process control systems for mining and coal mining.

Arising problems are the following:

- The complete testing of control system using the programmer's tools is almost impossible because of inability to connect to actual equipment.

- There is no way to make the complete testing of control system on-site because of inability to reproduce alarm situations or emergency situations.

- Startup and live testing time of control system onsite is limited.

The most suitable way to solve these problems is simulation [1]. A means for solving these problems is a model integrated with an actual process control system. The model can be run as a part of the actual process control system. On the other hand, the model can use software and hardware components of the actual process control system, for example, control programs, the operator workstation, or a programmable logic controller (PLC) in which the control programs executed, and others. The model can emulate processing equipment of the actual process control system.

Because of the importance of these problems, there are a large number of papers on the use of simulation in the development and optimization of mining systems [2, 3, 4, 5]. There are also a large number of simulation tools both universal simulation systems and specialized systems and packages for simulation of mining systems.

A number of models for the simulation of the following subsystems of coal mines were developed $[6,7]$ such as: belt conveyor subsystem, power supply subsystem, ventilation subsystem, pumping subsystem and longwall mining subsystem. These models are used at ICT for developing of process control systems for underground coal mines in Kuznetsk Coal Basin (Russia, Western Siberia).

A new model of the crushing-grading mill was developed. This model is used at ICT for developing of process control system of the crushing-grading mill "Apatite" (Russia, Kola Peninsula). All models were developed with the help of our own simulation system.

\section{The Simulation SySTEM}

A visual interactive Manufacturing and Transportation Simulation System (MTSS) is a process-oriented discrete simulation system intended to development and execution of models of technological processes $[8,9]$. MTSS is a set of program interfaces for creating elemental models as well as forming complex models from them. The elemental model is verified according to its specifications, ready-to-use simulation model of an equipment unit with capability of low-level control for it.

The elemental model consists of the following parts:

- Two-dimensional and three-dimensional animated graphic images.

- Input and output parameters.

- Functionality algorithm describing dependence between parameters.

- States that the elemental model can reach during the simulation process.

- Control commands defining switching process between elemental model states.

A model in MTSS is created by graphical connection of images of elemental models with the help of visual interactive interface. MTSS is also a tool for running of complex models built from elemental models. The running model performs the movement of the model time and visualization. Statistics is collected as well. Statistics are available as a short overview when model runs, and more statistics are available after model completion.

Elemental models can be then combined in a libraries forming simulation goal-specific tool, used by field specialists. 
Such tool can be an application for rapid creation of correct simulation model by mining engineers. Usually engineers have not enough qualification to create simulation models in details, but they know how to connect correctly elemental models to create the required topology. MTSS uses $2 \mathrm{D}$ as a graphical editor and 2D, 3D for visualization of model running. Such approach seems more natural for mining engineers, when all installations and machines appear first on 2D plans. 3D is more useful for visualizing complex vertical movement.

Process control systems often have two levels: the low level of equipment and simple control logic in it and the upper level of complex control of production. One of the distinguishing features of MTSS is a division of the logic of a simulation model into two parts: a low-level logic and an upper level logic.

Such division allows us not only to correlate to the usual structure of the process control systems but also to use such models for embedding them into actual process control systems in the following ways: to emulate equipment, to simulate upper level logic, and to send commands to actual process control system for debugging and testing. The division into upper and lower logics let us also organize a switch between various implementations of decomposition. It makes possible coexisting simulation of upper level logic and a proxy that allows communicating with the upper level logic of actual process control system.

The model of mining can communicate with a new process control system developed in ICT, to be a source of input signals, emulate equipment, test actual control program with simultaneous visualization of overall process of mining. This allows debugging and tuning of a new process control system in accordance with behavior of simulated system, even simulating various accidents. This permits to minimize time and costs on site for commissioning.

\section{The Model of CRUShING-Grading MiLl}

A new library of elemental models of equipment of the crushing-grading mill was developed within MTSS. This library contains the following elemental models:

- Product source. The product source provides the possibility to specify parameters of input stream of stone ore.

- Stone ore pass. This elemental model simulates a bunker-like object that takes and stores product from product source.

- Hydrohammer. The hydraulic hammer melts product portions what contain fractions that are not acceptable for stone ore pass.

- Vibrofeeder. The vibrofeeder gets the portion of product from stone ore pass and sends it to the next elemental model.

- Screw crusher. The screw crusher melts product again.
- Shaking grizzly. The shaking grizzly is transportation equipment.

- Conveyor. The conveyor is a long belt conveyor to deliver product on the long distances. The conveyor requires power supply chain to function (wires, transformer, and power generator).

- Bunker. The bunker is used for an intermediate storage of the end product.

- Crusher chamber. The crusher chamber is a simple object that just stores the product what may be loose during transportation and melting of the product in various elemental models.

The product (stone ore) is presented in the simulation like a portion of the product defined by product amount in $\mathrm{kg}$, its own fraction, amount of add-ons, and density. The product portions are generated in "Product source" according to its scenarios. Then these portions can be changed during their pass through the simulation model: its fraction can be changed (when it is melting), other product portions can be generated resulting in product split or product uniting, and add-ons can be excluded by a special elemental model. A product movement is presented in "Figure 1".

Product portions are generating in "Product source" ("input" in "Figure 1"), then they are passing to "Stone ore pass", decreasing their space left (originally it is $3 \mathrm{~m}^{3}$ in this simulation. $158 \mathrm{~kg}$ of the product with the density 1350 $\mathrm{kg} / \mathrm{m}^{3}$ takes $0.12 \mathrm{~m}^{3}$ which can be seen in fields "stp-approx space left $\mathrm{m} 3$ ", "in stone ore pass, kg"). Some amount of the product cannot be passed to "Stone ore pass" because it only accepts the product with fractions less than $800 \mathrm{~mm}$. So it is passed to "hydrohummer". "The hydrohummer" is manually controlled, it is turned off now, and we see that $25.5 \mathrm{~kg}$ of the product will be melted ("Melt, kg") and nothing is melted yet (counting property "Melted, kg"). On each step, $1.9 \mathrm{~kg}$ of the product is passed to working "Vibrofeeder". It can function only if "Screw crusher" is started. It passes its product portions to "Screw crusher" that melts everything to fractions of $350 \mathrm{~mm}$. "Shaking Grizzly" delivers melted product to "Conveyor" that is turned on. "Conveyor" takes every portion of a product and delivers it to the bunker. 1344 $\mathrm{kg}$ of the product is already processed as we may see, but $1631 \mathrm{~kg}$ is generated as a source product. A part of the product is in "Stone ore pass", the most of the rest is on "Conveyor" (that moves slowly and has a significant length). Other elements have big productivity in this configuration of the simulation model, therefore the product amount on them is small.

Since "Stone ore pass" has a limited capability, at some moment it can be not enough to handle the product portions. In this case, amount of a generated product that was not accepted by "Stone ore pass" will be shown in "input not accepted kg" variable. This product will be passed to "Stone ore pass" on the next simulation step. 


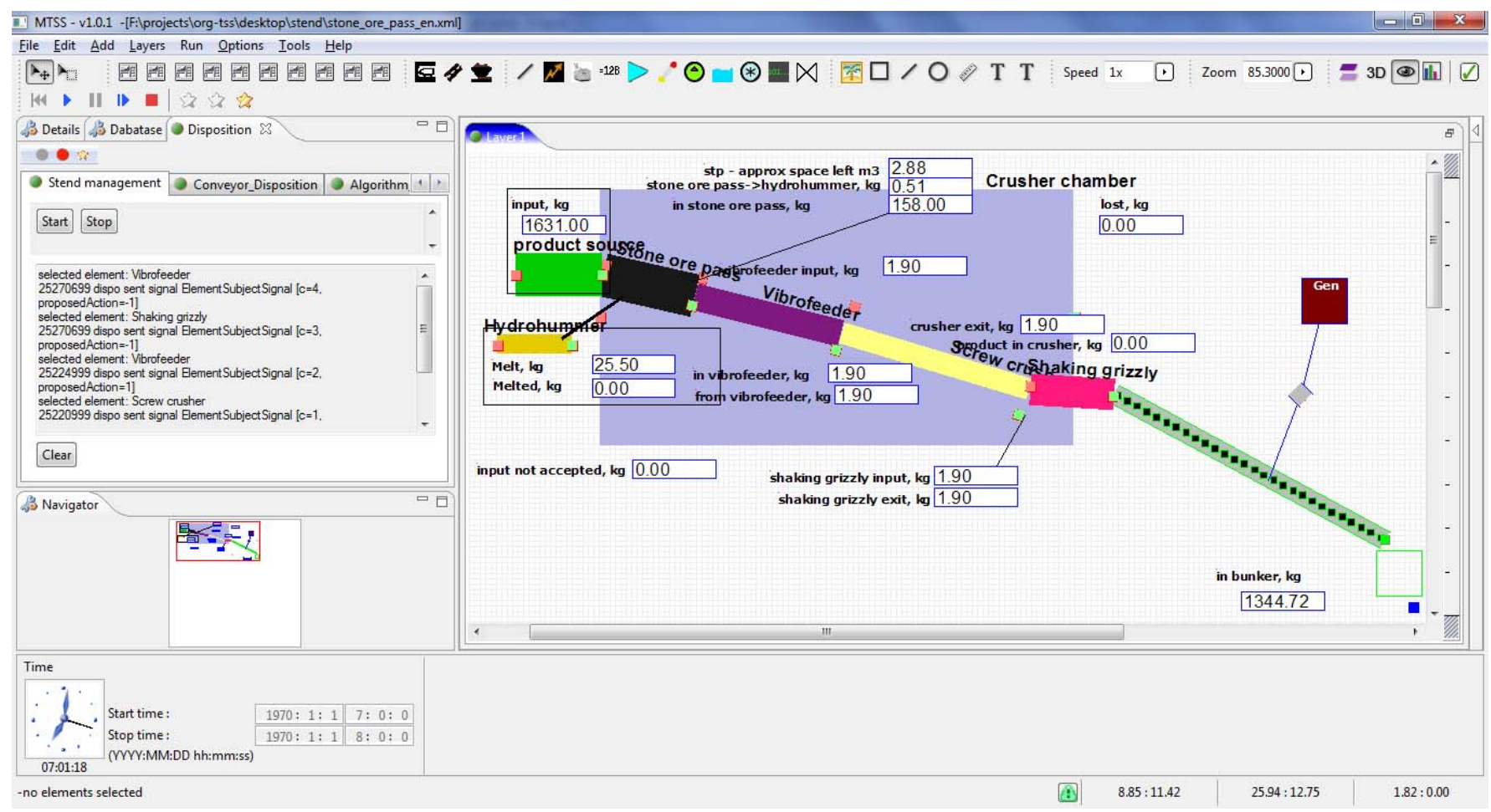

FIGURE I. THE MAIN WINDOWS OF MODEL OF CRUSHING-GRADING MILL

During the simulation, each elemental model can be started or stopped which will immediately lead to the change in the product amount in the bunker. "Vibrofeeder", "Screw crusher" and "Shaking grizzly" have their own max input capabilities and their advance speed. Small capabilities will lead to overflowing of "Stone ore pass", and big ones will lead to always empty "Stone ore pass". Also the "Conveyor" has the length and the speed that can lead to lots of the product to be stuck on it and not appear in the bunker.

\section{Testing of Process Control System of CRUSHING-GRADING MILL}

A software/hardware test bed for testing the process control systems using a simulation model is developed at ICT. The structure of software/hardware test bed is shown in "Figure 2".

The process control system of crushing-grading mill is developed at ICT employing Wonderware InTouch. The Simulation System MTSS includes the corresponding OPC client allowing the model of crushing-grading mill to interact with the process control system of the crushing-grading mill.

The model simulates the coordinated values for input signals from the processing equipment sensors of the crushing-grading mill in physical units of measurement and sends them to the process control system. An operator of the process control system sends commands to the processing equipment of the crushing-grading mill. In accordance with the logic of the control program of the process control system these control commands are sent to the actuators of the real system, but they arrive at the model. In the model this commands "is executed" generating the corresponding changes in the state of the processing equipment. The new values of the input signals are sent to the process control system, which tests the correctness of the command information execution. Thus the process control system "doesn't know" in what environment - actual or simulated it works.

All this helps to debug and test the upper level of the process control system, control programs, executed in PLC, with incomplete set of processing equipment as well as in the case of emergencies.

The own SCADA-System is implemented in ICT, with its help a number of process control systems were developed. Each process control system was supplied with its own model for testing.

In order to test the low level of process control systems with using the model and the test bed we have an opportunity to generate the values of certain input signals in electrical units in the form they are read directly from the sensors. These simulated signals are directly sent to the input of the corresponding input/output modules and PLCs. So the functionality of the whole scheme shown in "Figure 2" is checked. 


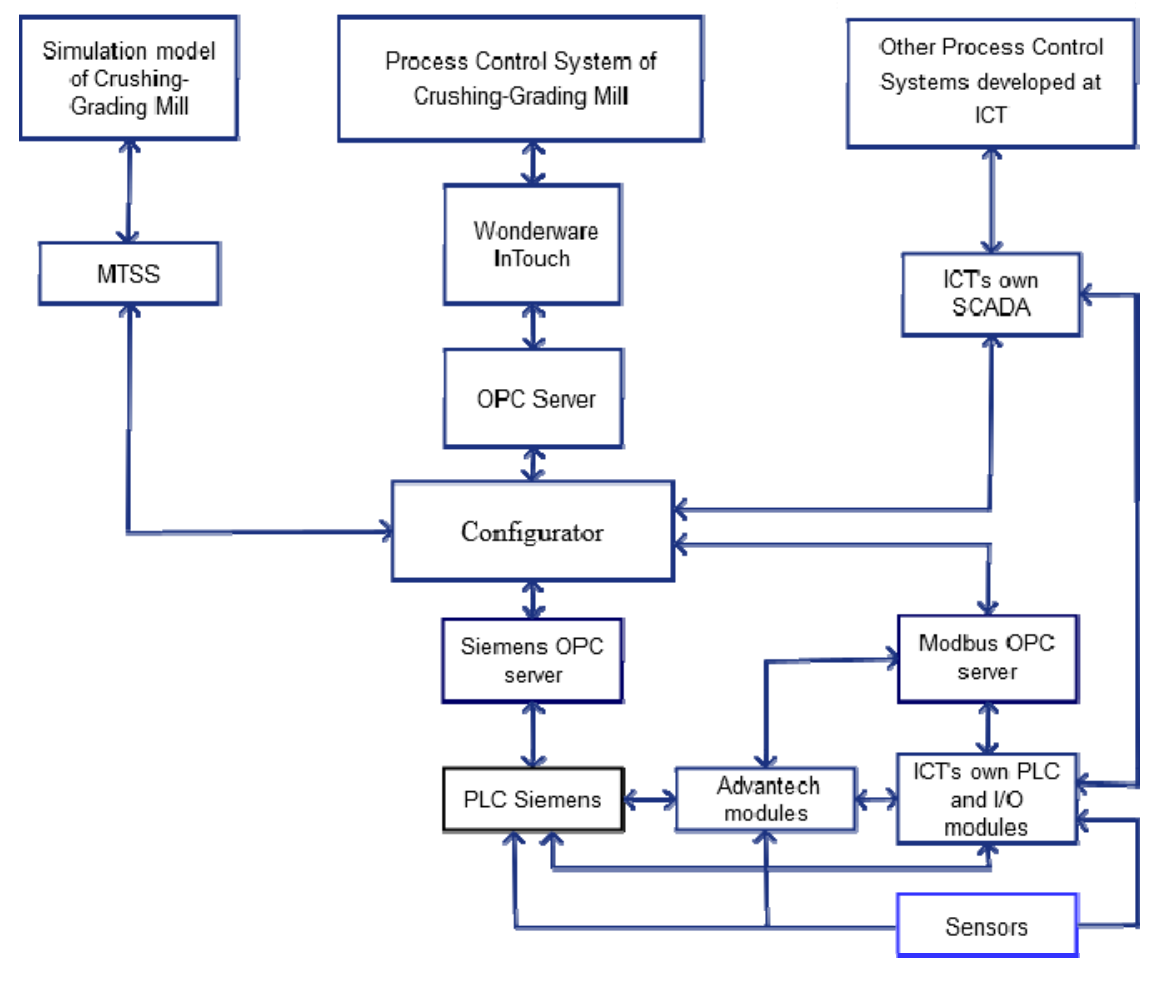

FIGURE II. The scheme of testing of process contol system.

\section{CONCLUSION}

Simulation system MTSS enables engineers with little experience in simulation, investigation and optimization of mining systems to solve complex engineering problems to assess the effectiveness of automation and choice of the optimal technology, which eventually will reduce the costly risks during the design and optimization technological processes in the mining.

Simulation system MTSS can be used not only for simulation of existing mining techniques but also for perspective robotized techniques $[10,11]$.

\section{ACKNOWLEDGMENT}

This research was financially supported by the Russian Foundation for Basic Research (project 16-47-420490 r a, and project 16-07-01179 a).

\section{REFERENCES}

[1] J.R. Sturgul, "Modelling and Simulation in Mining - Its Time Has Finally Arrived," Simulation, 76(5), 2001, pp. 286-288.

[2] J. Greberg, F. Sundqvist, "Simulation as a tool for mine planning," in Proceedings of Second International Future Mining Conference, 2011, pp 273-278.

[3] D. Cai, E. Baafi \& I. Porter, "Modelling a longwall production system using flexsim 3D simulation software," in R. Singhal, E. Topal, K. Fytas, M. Yellishetty \& A. Mehrotra (Eds.), Mine planning and equipment selection, 2012, pp. 107-114.
[4] C. Meng, S.S. Nageshwaraniyer, A. Maghsoudi, Y. Son, and S. Dessureault. "Data-driven Modeling and Simulation Framework for Material Handling Systems in Coal Mines," Computers \& Industrial Engineering, 2013, pp. 766-779.

[5] M. Fioroni, L. Santos, L. Franzese, I. Santana, G. Telles, J. Seixas, B. Penna and G. Alkmim, "Logistic Evaluation of an Underground mine Using Simulation," in Proceedings of the 2014 Winter Simulation Conference, 2014, pp. 1855-1865.

[6] V. Okolnishnikov, S. Rudometov, S. Zhuravlev, "Simulating the Various Subsystems of a Coal Mine", Engineering, Technology \& Applied Science Research, Vol. 6, No. 3, 2016, pp. 993-999.

[7] V. Okolnishnikov, S. Rudometov, S. Zhuravlev and V. Sinoviev, "Simulation of longwall coal mining technologies," in Proceedings of the 28TH European Modeling and Simulation Symposium. Simulation in Industry - 2016, 2016, pp. 212-215.

[8] V.V. Okolnishnikov, S.V. Rudometov, "A System for Computer Simulation of Technological Processes," in Proceedings of 7th IFAC Conference on Manufacturing Modelling, Management, and Control, MIM 2013. 2013. pp. 653-658.

[9] V.V. Okolnishnikov, S.V. Rudometov, "A System for Computer Simulation of Technological Processes," St. Petersburg State Polytechnic University Journal. Computer Science. Telecommunications and Control Systems, 1 (181), 2014, pp. 62-68.

[10] V.V. Sinoviev, A.N. Starodubov, M.U. Dorofeev and V.V. Okolnishnikov, "Discrete Event Simulation Robotic Technology of Mining," Mathematics and Computers in Science and Industry. Mathematics and Computers in Science and Engineering Series - 50, 2015, pp. 75-77.

[11] V.V. Sinoviev, V.V. Okolnishnikov, A.N.Starodubov and Dorofeev, "Approach to Effectiveness Evaluation of Robotics Technology in Mining Using Discrete Event Simulation," International Journal of Mathematics and Computers in Simulation, 10, 2016, pp. 123-128. 